ISSN 1420-3049

www.mdpi.com/journal/molecules

Article

\title{
Antiradical and Cytoprotective Activities of Several C-Geranyl-substituted Flavanones from Paulownia tomentosa Fruit
}

\author{
Aleš Zima ${ }^{1}{ }^{1}$, Jan Hošek ${ }^{1}$, Jakub Treml ${ }^{1}$, Jan Muselík ${ }^{2}$, Pavel Suchý ${ }^{3}$, Gabriela Pražanová ${ }^{3}$, \\ Ana Lopes ${ }^{4}$ and Milan Žemlička ${ }^{1}$ \\ 1 Department of Natural Drugs, Faculty of Pharmacy, University of Veterinary and Pharmaceutical \\ Sciences Brno, Brno, Czech Republic \\ 2 Department of Pharmaceutics, Faculty of Pharmacy, University of Veterinary and Pharmaceutical \\ Sciences Brno, Brno, Czech Republic \\ 3 Department of Human Pharmacology and Toxicology, Faculty of Pharmacy, University of \\ Veterinary and Pharmaceutical Sciences Brno, Brno, Czech Republic \\ 4 Faculty of Pharmacy, University of Lisbon, Lisbon, Portugal \\ * Author to whom correspondence should be addressed; E-Mail: zimaa@vfu.cz; \\ Tel.: +420541562839 .
}

Received: 17 July 2010; in revised form: 12 August 2010 / Accepted: 27 August 2010 /

Published: 31 August 2010

\begin{abstract}
Antiradical and cytoprotective activities of several flavanones isolated from Paulownia tomentosa (Thunb.) Steud. (Scrophulariaceae) have been evaluated using different in vitro and in vivo methods. The capacity of flavanones to scavenge radicals was measured in vitro by means of DPPH and ABTS assays, the inhibition of hydroxyl radicals produced in Fenton reactions, FRAP, scavenging superoxide radicals using enzymatic and nonenzymatic assays and the inhibition of peroxynitrite-induced nitration of tyrosine. The in vivo testing involved measuring the cytoprotective effect of chosen flavanones against alloxan-induced diabetes in mice. The activity of tested compounds was expressed either as a Trolox $^{\circledR}$ equivalent or was compared with rutin or morine as known antioxidant compounds. The highest activity in most tests was observed for diplacone and 3 '-Omethyl-5'-hydroxydiplacone, and the structure vs. the antioxidant activity relationship of geranyl or prenyl-substituted flavonoids with different substitutions at the B and $\mathrm{C}$ ring was discussed.
\end{abstract}


Keywords: Paulownia tomentosa; prenyl; flavanone; antiradical; cytoprotective

\section{Introduction}

The so-called civilization diseases are, especially in the Western world, complex illnesses resulting from bad and unhealthy life styled as well as impaired environmental conditions. The incidence of civilization disease is also connected to the increase of the World's population and extended life-times. Such diseases are, for example, neurodegenerative disorders (senile dementia, Alzheimer's disease), cardiovascular illnesses, diabetes mellitus type 2, and cancer. It is now common knowledge that the formation of reactive oxygen species (ROS) and/or nitric species (RNS) is highly implicated in the pathogenesis of such diseases [1,2]. ROS/RNS can be both harmful and beneficial in humans. The beneficial effects of ROS involve, for instance, the defense against infectious agents and several cellular signaling systems. In contrast, when released in high concentration, ROS/RNS can inflict damage to cellular components (lipids, membranes, nucleic acids, etc.). This situation can lead to oxidative stress. Oxidative stress has been defined as "a disturbance in the pro-oxidant and antioxidant balance in favor of the former, leading to potential damage" [2]. To counterbalance the harmful effects of ROS/RNS, organisms are protected by different antioxidants systems, which inhibit or retard the oxidation damage of cells and/or physiological processes $[3,4]$.

Flavonoids are a structurally variable group of polyphenolic compounds that are ubiquitous in Nature. Up until the present, over 8,000 flavonoids have been identified [5]. The beneficial health effects of flavonoids are especially attributed to their antioxidant activity. Attempts to establish the relationship between structure and their radical-scavenging capacity have been successful [5-7]. The activity of flavonoids depends on the position of hydroxy, methoxy, geranyl or other group substitutions. The ability to act as an efficient antioxidant does not depend solely on the availability of phenolic hydrogens but also on the possible stabilization of the resulting radical $[7,8]$.

Paulownia tomentosa (Thunb.) Steud. (Srophulariaceae) is a potent source of biologically active $C$ geranyl flavanones. According to scientific literature, these compounds have shown cytotoxic, antibacterial and antiradical properties [9-11]. In this present work, flavonoids with a geranyl and prenyl substitution isolated from $P$. tomentosa were evaluated in vitro in antiradical assays (DPPH, ABTS, the inhibition of Fenton reaction, inhibition of peroxynitrite induced nitration of tyrosine, FRAP, and the inhibition of superoxide) and in vivo for their cytoprotective effects against alloxaninduced diabetes.

\section{Results and Discussion}

The ability of variously substituted flavonoids from $P$. tomentosa, with a geranyl or prenyl chain at position 6 , to act as potential antioxidants was tested. The tested flavanones showed different degrees of activity in all of the assays that were used. The activity of these compounds was expressed as TEAC (Trolox Equivalent Antioxidant Capacity) for ABTS, DPPH, FRAP, and the inhibition of peroxynitrite induced tyrosine nitration. The TEAC value is based on the ability of an antioxidant to scavenge radicals relative to the radical scavenging ability of the water-soluble vitamin $E$ analogue, Trolox ${ }^{\circledR}$ [12], and is expressed as multiples of the activity of Trolox ${ }^{\circledR}$. Rutin was used as the standard of activity 
for comparing the effects in assays based on the inhibition of superoxide radical and inhibition of Fenton reaction. Morine was used as a reference compound in the alloxan-induced pancreatic damage test.

The evaluated compounds all had a flavanone skeleton except $\mathbf{5}$ and $\mathbf{1 0}$ (flavanonol structures). Compounds 1-9 were substituted with a geranyl side chain at the position 6 (hydroxylated geranyl present at $\mathbf{4}$ and $\mathbf{8}), \mathbf{1 0}$ was substituted by a prenyl chain at the same position. The compounds had different substitution at the $\mathrm{B}$ and $\mathrm{C}$ ring (Table 1).

Table 1. Structures of compounds tested.

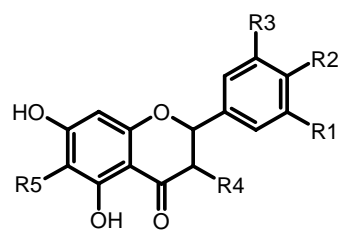

\begin{tabular}{l|ccccc}
\hline \multicolumn{1}{c|}{ Compound / substituent } & $\mathbf{R 1}$ & $\mathbf{R 2}$ & $\mathbf{R 3}$ & $\mathbf{R 4}$ \\
\hline Diplacone (1) & $\mathrm{OH}$ & $\mathrm{OH}$ & $\mathrm{H}$ & $\mathrm{H}$ \\
Mimulone (2) & $\mathrm{H}$ & $\mathrm{OH}$ & $\mathrm{H}$ & $\mathrm{H}$ \\
3'-O-methyldiplacone (3) & $\mathrm{OMe}$ & $\mathrm{OH}$ & $\mathrm{H}$ & $\mathrm{H}$ \\
Tomentodiplacone (4) & $\mathrm{OMe}$ & $\mathrm{OH}$ & $\mathrm{H}$ & $\mathrm{H}$ \\
3'-O-methyldiplacol (5) & $\mathrm{OMe}$ & $\mathrm{OH}$ & $\mathrm{H}$ & $\mathrm{OH}$ \\
3'-O-methyl-5'-OH-diplacone (6) & $\mathrm{OMe}$ & $\mathrm{OH}$ & $\mathrm{OH}$ & $\mathrm{H}$ \\
3'-O-methyl-5'-O-methyldiplacone (7) & $\mathrm{OMe}$ & $\mathrm{OH}$ & $\mathrm{OMe}$ & $\mathrm{H}$ \\
Tomentodiplacone B (8) & $\mathrm{OMe}$ & $\mathrm{OH}$ & $\mathrm{H}$ & $\mathrm{H}$ \\
Schizolaenone C (9) & $\mathrm{OH}$ & $\mathrm{H}$ & $\mathrm{OH}$ & $\mathrm{H}$ \\
6-isopentenyl-3'- $\boldsymbol{O}$-methyltaxifolin (10) & $\mathrm{OMe}$ & $\mathrm{OH}$ & $\mathrm{H}$ & $\mathrm{OH}$
\end{tabular}

2.1. ABTS, DPPH, FRAP, the inhibition of peroxynitrite induced tyrosine nitration

Both the ABTS and DPPH tests identified the promising activity of compound $\mathbf{1}$ (TEAC $_{\mathrm{ABTS}} 3.2$ and $\left.\mathrm{TEAC}_{\mathrm{DPPH}} 1.06\right)$ and compound 6 (TEAC $\mathrm{TBRS}_{\mathrm{ABT}} 1.66$ and $\left.\mathrm{TEAC}_{\mathrm{DPPH}} 0.98\right)$. The reducing potential of the compounds $(4,8$ and 9 were excluded because of insufficient material), was evaluated in the FRAP assay, where compounds 7 (1.189) and 6 (0.741) showed the highest activity. The ability of the tested compounds to decrease peroxynitrite-induced nitration of tyrosine was investigated as well. The tested compounds showed similar results of activity. The highest ability to prevent against tyrosine nitration showed 9. The results of the above-mentioned experiments are summarized in Table 2.

The structure and antioxidant activity relationships of flavonoids is determined by a) the ortho 3',4'-dihydroxy substitution in the B ring, b) the meta 5,7-dihydroxy substitution in the A ring, c) the 2,3-double bond in $\mathrm{C}$ ring, d) the 4-keto substitution in $\mathrm{C}$ ring, e) the 3-hydroxyl group in the $\mathrm{C}$ ring. The spatial arrangement of the substitution is perhaps a greater determinant of antioxidant activity than the flavan skeleton $[13,14]$. Another substitution influencing antioxidant activity is $O$-methylation, which may decrease antioxidant activity [15]. Steric effects may also induce the suppression of 
antioxidant activity; the $\mathrm{B}$ ring is particularly sensitive to the position of the methoxy group and $2^{\prime}-O-$ methyl, 4'-hydroxy substitution at the flavonoid B ring abolishes antioxidant activity, whereas 2'hydroxy, 4'-O-methyl derivatives show activity. The methylation of the $3^{\prime}, 4^{\prime}$ ortho dihydroxy group leads to the decrease of scavenging [16]. Similar structure-activity relationships can also be deduced from the results presented here. Compounds with an ortho-dihydroxy substitution of the flavanone Bring showed the highest activity, but the activity of methoxylated compounds $(\mathbf{3}, \mathbf{4}, \mathbf{5}, \mathbf{7}, \mathbf{8})$ or compound with para located hydroxyl (2) was much lower. The 3-OH substitution of 5 did not affect activity, similar to the hydroxy substitution of the geranyl side chain (3 in comparison with $\mathbf{4}$ and $\mathbf{8}$ ).

These basic rules were established based on the DPPH, ABTS and similar antioxidant assays and may differ slightly from the results obtained from other tests. Different influence of $O$-methylation on activity is described for FRAP and the inhibition of peroxynitrite induced nitration of tyrosine. The increase of reduction ability in FRAP may be evoked by partial $O$-methylation of the B ring. The presence of an electron-donating moiety on the B ring as the methoxy group confers the higher reducing capability, but total number of hydroxy groups and other mentioned structural properties are necessary and enhance the antioxidant activity of the flavonoids [17].

Previously published studies also show the low effect of $O$-methylation on peroxynitrite induced nitration of tyrosine, when the different position of the $O$-methoxy substitution of antocyanins did not influence their activity [18]. It corresponds with results presented here, which show only a low influence of $O$-methylation on peroxynitrite induced nitration of tyrosine (compare diplacone (1) and 3'-O-methyldiplacone (3)). Results also showed that compounds with $O$-methyl group at similar position on the B-ring (3-8) have similar antiperoxynitrite activity, while the activity of mimulone (2), compound with $p-\mathrm{OH}$ substituted B-ring is low. Also, the changes on the geranyl side chain did not affect the ability of the compounds tested to prevent tyrosine nitration $(4,8,10)$.

Table 2. Antioxidant activities of compounds 1-9 determined by using ABTS, DPPH, FRAP, the inhibition of tyrosine nitration (activity expressed as TEAC - ability of the sample to scavenge the radical relative to the radical scavenging ability of Trolox ${ }^{\circledR}$. Value are multiples of activity of Trolox ${ }^{\circledR}$ ) and superoxide scavenging activity (expressed as $\%$ of inhibition at $50 \mu \mathrm{M}$ concentration).

\begin{tabular}{|c|c|c|c|c|c|c|}
\hline & \multirow[t]{2}{*}{ ABTS } & \multirow[t]{2}{*}{ DPPH } & \multirow[t]{2}{*}{ FRAP } & \multirow{2}{*}{$\begin{array}{c}\text { Inhibition of. } \\
\text { peroxynitrite } \\
\text { induced tyrosine } \\
\text { nitration }\end{array}$} & \multicolumn{2}{|c|}{$\begin{array}{c}\text { Superoxide scavenging } \\
\text { activity }\end{array}$} \\
\hline & & & & & Enzymatic & $\begin{array}{c}\text { Non- } \\
\text { enzymatic }\end{array}$ \\
\hline 1 & $3.2 \pm 0.01$ & $1.06 \pm 0.04$ & $0.522 \pm 0.01$ & $0.84 \pm 0.01$ & 45.2 & 25.9 \\
\hline 2 & $1.7 \pm 0.01$ & $0.02 \pm 0.01$ & $0.051 \pm 0.00$ & $0.09 \pm 0.01$ & $-^{a}$ & $-^{a}$ \\
\hline 3 & $1.4 \pm 0.00$ & $0.12 \pm 0.02$ & $0.118 \pm 0.00$ & $0.80 \pm 0.03$ & $-^{a}$ & $-^{a}$ \\
\hline 4 & $1.61 \pm 0.01$ & $0.14 \pm 0.04$ & $-^{\mathrm{a}}$ & $0.82 \pm 0.01$ & $-^{\mathrm{a}}$ & $-^{\mathrm{a}}$ \\
\hline 5 & $1.62 \pm 0.01$ & $0.10 \pm 0.00$ & $0.127 \pm 0.01$ & $0.74 \pm 0.01$ & $-^{\mathrm{a}}$ & $-{ }^{\mathrm{a}}$ \\
\hline 6 & $1.66 \pm 0.01$ & $0.98 \pm 0.03$ & $0.741 \pm 0.01$ & $0.84 \pm 0.01$ & 71.2 & 29.5 \\
\hline 7 & $1.60 \pm 0.01$ & $0.29 \pm 0.02$ & $1.189 \pm 0.06$ & $0.83 \pm 0.02$ & $-{ }^{a}$ & $-^{a}$ \\
\hline 8 & $0.97 \pm 0.03$ & $0.12 \pm 0.00$ & $-^{\mathrm{a}}$ & $0.82 \pm 0.02$ & $-^{\mathrm{a}}$ & $-^{\mathrm{a}}$ \\
\hline 9 & $-{ }^{\mathrm{a}}$ & $-^{\mathrm{a}}$ & $-{ }^{\mathrm{a}}$ & $0.93 \pm 0.02$ & $-{ }^{\mathrm{a}}$ & $-{ }^{\mathrm{a}}$ \\
\hline Rutin & $-^{\mathrm{a}}$ & $-^{\mathrm{a}}$ & $-^{\mathrm{a}}$ & $\mathrm{-a}^{\mathrm{a}}$ & 50.2 & 43.6 \\
\hline
\end{tabular}

${ }^{a}$ Not determined. 


\subsection{Superoxide scavenging activity assay}

Both flavonoids 1 and $\mathbf{6}$ showed a promising scavenging of radicals. According to the scientific literature, there are some requirements in the arrangement of substituents for superoxide scavenging and the inhibition of xanthinoxidase (XO). Searching the literature led however to conflicting conclusions about superoxide scavenging activity and the inhibition of $\mathrm{XO}$ by flavanones. Tested samples met the structural conditions for superoxide scavenging: 5,7-dihydroxy substitution, 3',4'-dihydroxy substitution, and 4-oxo group [19,20]. These conditions are stated for the direct scavenging of superoxide, but not for the inhibition of XO. Some authors state that flavanones are not able to inhibit XO because they lack the $C-2$ - $C-3$ double bond. This double bond causes planarity of the $\mathrm{A}, \mathrm{C}$ and $\mathrm{B}$ rings group due to the conjugation effect and is an important factor for $\mathrm{XO}$ inhibition [19]. On the other hand, according to some authors, flavanones might inhibit XO due to the fact that their chemical structure is closely related to hypoxanthine, xanthine, and uric acid, and may act as XO substrate analogs [21].

Based on the results of the ABTS and DPPH assays, the activity of compound $\mathbf{1}$ and compound $\mathbf{6}$ was measured using a superoxide-scavenging assay. Two systems for generating superoxide radical were used: enzymatic and non-enzymatic. Both assays, as described in past literature, were primary for the proper evaluation of hydrophilic compound activity because of the aqueous character of the reaction mixture [22]. In this work, the optimization of these assays for hydrophobic compounds (C-6 lipophilic substituent) was carried out, and the activity of the compounds tested was compared with rutin at equimolar concentrations of $50 \mu \mathrm{M}$.

Some differences between the results of enzymatic and non-enzymatic assays were found (Table 2). In the non-enzymatic test, the activities of the compounds tested were similar (1 25.9\%, $629.5 \%)$, but lower than the activity of rutin (43.6\%). The results of the enzymatic assay showed higher activities of $\mathbf{1}, \mathbf{6}$ and rutin, in comparison with the non-enzymatic assay. Compound $\mathbf{6}$ showed the highest activity (71.2\%), significantly higher than rutin (50.2\%). From these results it can be concluded, that geranylated flavanones can also act as XO inhibitors and, if needed, serve as compounds for the modeling of more potent structures.

\subsection{Inhibition of Fenton reaction assay}

Different methods can be used for the measurement of hydroxyl radical scavenging activity [23]. In this study, the Fenton reaction system generating a hydroxyl radical with plasmid DNA as a detection system was used to bring the assay closer to in vivo conditions. Plasmid DNA was used as a target for the attack of $\mathrm{OH}^{*}$ radicals. Plasmid DNA is constituted from a circular double strand of nucleic acids in its native supercoiled conformation, also known as $\mathrm{CCC}$ (covalently closed circle). The attack of $\mathrm{OH}^{\circ}$ degrades the DNA into series of degradation products. The open circle (OC) conformation is the first step of degradation and it is characterized by having only one strand cut, therefore remaining in its circular conformation. The linear (L) form is the result of a cut in both DNA strands. All these forms are visible by electrophoretic separation.

Oxidative damage of biomacromolecules, including DNA, is considered one of the most dangerous actions of ROS. Plasmid DNA as a model of oxidative disruption was successfully used in several 
studies [24,25]. The activity of the compounds tested was expressed as a "compounds ratio/ rutin ratio". Compounds ratio and rutin ratio means ratio of area under curve (AUC), which demonstrates concentration of DNA (see section 3.6), of CCC form /AUC of OC form plus AUC of L form [i.e. $\mathrm{CCC} /(\mathrm{OC}+\mathrm{L})]$. The higher value means a higher content of $\mathrm{CCC}$-form, thus a lower degradation of plasmid DNA. AUCs of individual plasmid forms were obtained from the densitometric evaluation of electrophoretograms. Among the compounds tested, the highest activity was found for compound 6 (ratio 2,565) and compound 1 (ratio 0,892). The compounds tested can be ordered in decreasing activity: 3'-O-methyl-5'-hydroxydiplacone (6) $>$ diplacone (1) $>$ mimulone (2) $>3^{\prime}$-O-methyldiplacone (3) > 3'-O-methyldiplacol (5) > 3'-O-methyl-5'-O-methyldiplacone (7) > 6-isopentenyl-3' $O$-methyltaxifolin (10). Table 3 displays the results of this assay in detail. Among the compounds examined for their antioxidant effect, only the two compounds with the ortho-dihydroxy substitution at ring $\mathrm{B}$ diplacone (1) and 3'-O-methyl-5'-hydroxydiplacone (6), were significantly active. This may imply that the ortho hydroxy substitution is important for the antioxidant activity of such compounds, similarly in the results shown in the DPPH test and FRAP (with exception of compound 7). 6-isopentenyl-3'-O-methyltaxifolin (10) showed virtually no antioxidant activity in the Fenton reaction inhibition assay, being the only flavanone tested that lacks the geranyl group (compare $\mathbf{5}$ and 10).

Table 3. Results of Fenton reaction inhibition assay. Rutin at the molar excess of 50:1 or 10:1 to DNA base pare was compared with the tested compounds at the same molar excess. AUC - area under curve; CCC - covalent closed circle (superhelical form of plasmid); L - linear form of plasmid; OC - open circle (circular form of plasmid).

\begin{tabular}{cccccc}
\hline \multirow{2}{*}{ Compound } & \multicolumn{3}{c}{ AUC } & $\begin{array}{c}\text { Ratio CCC/ } \\
(\mathbf{O C}+\mathbf{L})\end{array}$ & $\begin{array}{c}\text { Compound ratio/ } \\
\text { Rutin ratio }\end{array}$ \\
\cline { 2 - 4 } & $\mathbf{C C C}$ & $\mathbf{O C}$ & $\mathbf{L}$ & & 0.332 \\
$\mathbf{1}(50: 1)$ & 569 & 1618 & 98 & 0.121 & 0.135 \\
$\mathbf{1}(10: 1)$ & 453 & 3272 & 458 & 0.202 & 0.543 \\
$\mathbf{3}(50: 1)$ & 708 & 3271 & 231 & 0.066 & 0.073 \\
$\mathbf{3}(10: 1)$ & 229 & 3170 & 294 & 0.169 & 0.454 \\
$\mathbf{7}(50: 1)$ & 514 & 2854 & 193 & & 0.279 \\
$\mathbf{7}(10: 1)$ & 564 & 2173 & 73 & 0.251 & 1 \\
Rutin (50:1) & 1288 & 3207 & 254 & 0.372 & 1 \\
Rutin (10:1) & 1942 & 1955 & 207 & 0.898 & - \\
Natural plasmid & 2790 & 386 & 193 & 4.819 & 0.553 \\
$\mathbf{2}(50: 1)$ & 439 & 634 & - & 0.692 & 0.199 \\
$\mathbf{2}(10: 1)$ & 152 & 1502 & - & 0.101 & 2.565 \\
$\mathbf{6}(50: 1)$ & 1289 & 402 & - & 3.206 & 0.921 \\
$\mathbf{6}(10: 1)$ & 656 & 1406 & - & 0.467 & 0.094 \\
$\mathbf{1 0}(50: 1)$ & 194 & 1556 & 96 & 0.117 & 0.183 \\
$\mathbf{1 0}(10: 1)$ & 189 & 1915 & 122 & 0.093 & 1 \\
Rutin (50:1) & 1055 & 843 & - & 1.251 & - \\
Rutin (10:1) & 806 & 1591 & - & 0.507 & - \\
Natural plasmid & 1507 & - & - & - & - \\
$\mathbf{5}(50: 1)$ & 505 & 1379 & - & 0.366 & 1 \\
$\mathbf{5}(10: 1)$ & - & 1373 & - & - & 1 \\
Rutin (50:1) & 1155 & 1493 & 57 & 0.745 & - \\
Rutin (10:1) & 535 & 1788 & 47 & 0.292 & \\
Natural plasmid & 2166 & 258 & - & 8.395 & \\
\hline
\end{tabular}




\subsection{Cytoprotective effect against alloxan-induced diabetes}

The single in vivo test was based on monitoring of cytoprotective effect against alloxan-induced diabetes. Alloxan transported into $\beta$-cells of Langerhans islets of mouse pancreas is transformed to dialuric acid, which re-oxidation leads back to alloxan. Several free radicals, such as superoxide, hydroxyl radical or alloxan radical, are formed during this intracellular red/ox process. These free radicals selectively destroy the $\beta$-cells, which results in insulin production decrease in treated mice [26]. Flavonoids, as known antioxidants, may prevent the progressive impairment of pancreatic $\beta$-cell function due to oxidative stress [27]. Administration of diplacone (1) and mimulone (2) was not found to reduce the blood glucose levels in alloxan-induced diabetic mice (Figure 1). The only exception was the reduction $(\mathrm{p} \leq 0.05)$ in blood glucose levels of animals treated with diplacone (1) on the first day of the experiment.

Diplacone (1) showed significant antioxidant activity in the in vitro tests. Whereas the damage of $\beta$ cells of Langerhans islets occurs by means of free radicals formed during red/ox reactions (see above), a cytoprotective activity of diplacone (1) with consequent decrease of glycemia level was expected in the test focused on cytoprotective effect against alloxan-induced diabetes, as it was described by Soto et al. [28]. However, in the present in vivo experiment, only minor changes in glycemia level in groups treated with diplacone (1) were found. This fact could be caused by low dose of diplacone (1) used for experiment [28].

On the other hand, some cytoprotective effect of diplacone (1) was proved by histopathological analysis of pancreatic tissue (Figure 2-5). This observation supports fact that flavonoids may act as a cytoprotective substances [29]. Results of cytoprotective activity assay could be correlated with a higher activity of diplacone (1) compared with the other tested compounds.

Figure 1. Levels of glycemia mmol/L as determined in alloxan induced diabetes testing of $\mathbf{1}$ and $\mathbf{2}$.

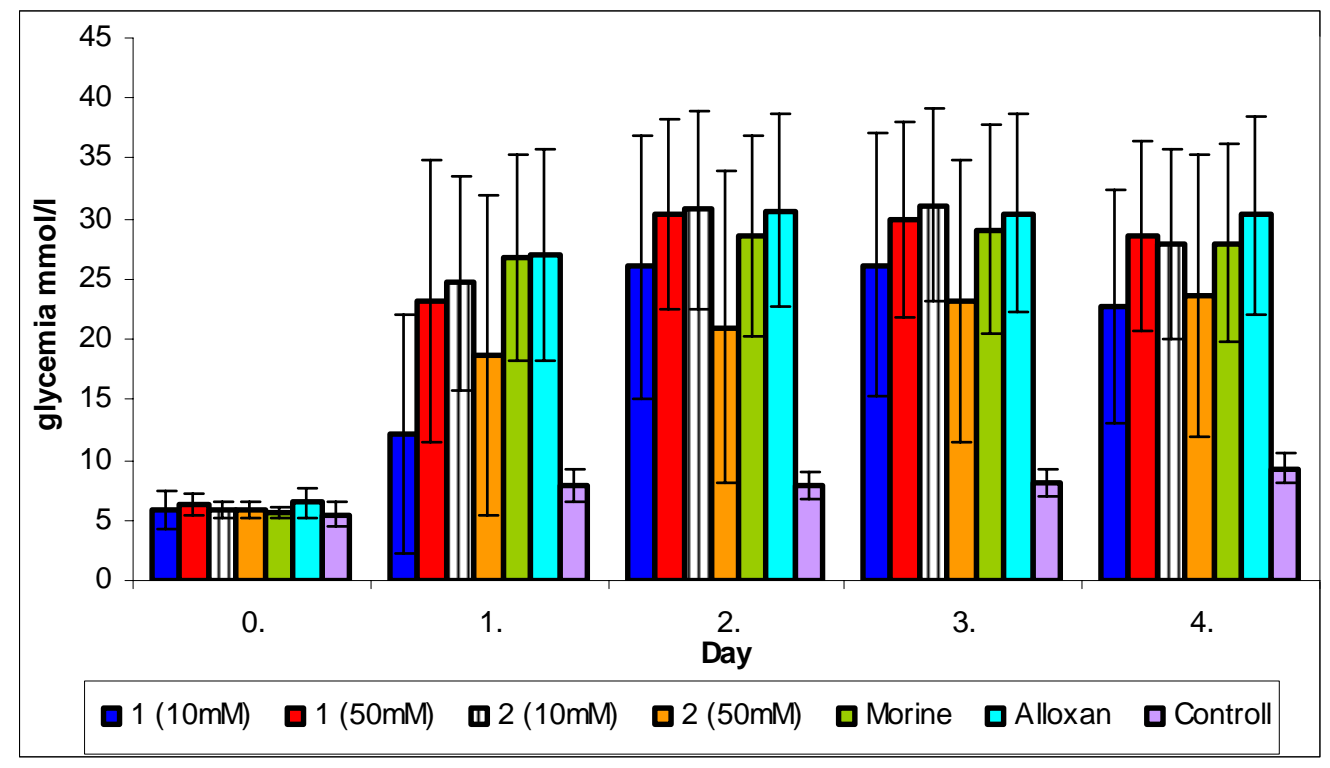


Figure 2. Microphotograph of the pancreas of control mice (HE 400×). Pancreatic islets with distinctly-outlined cell borders (physiological findings).

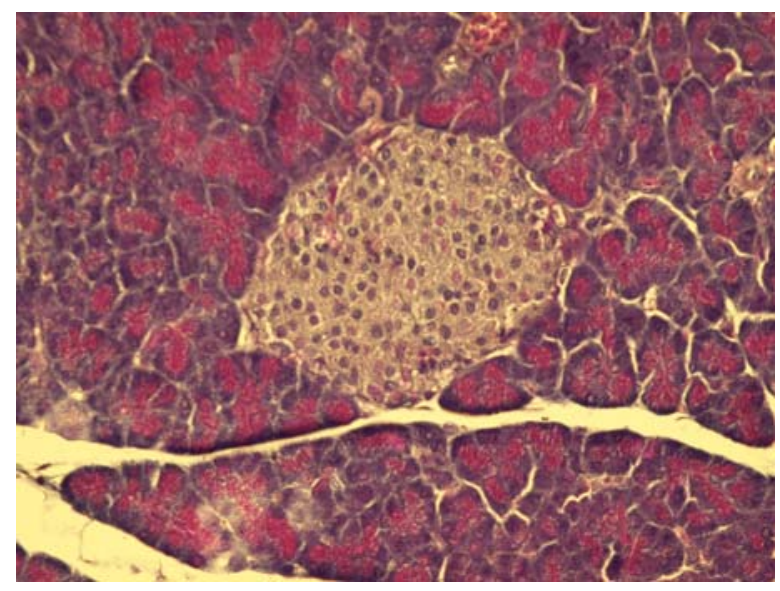

Figure 3. Microphotograph of the pancreas of alloxan-treated mice (HE 600×). Rudimental reaction to the destroyed pancreatic islet.

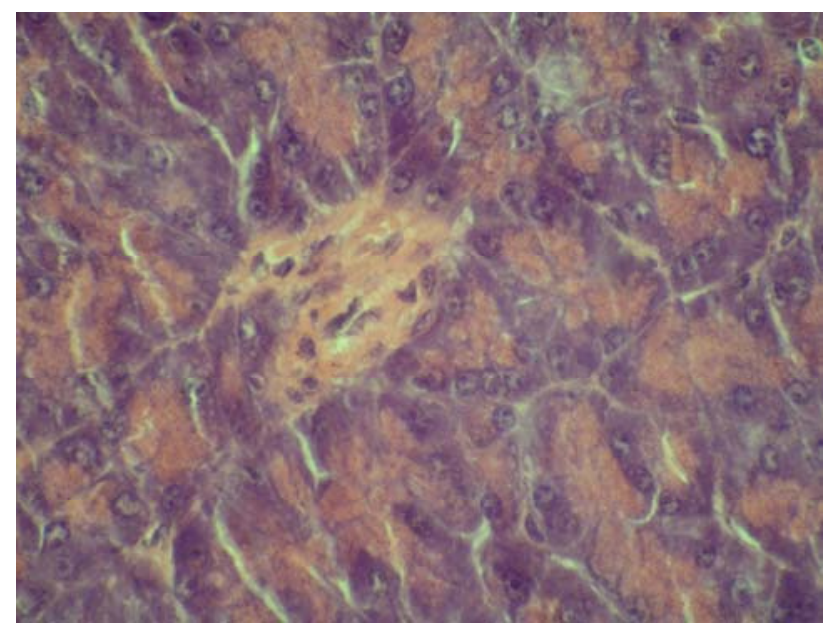

Figure 4. Microphotograph of the pancreas - the effect of mimulone (2) on the pancreatic histopathology of diabetic mice (HE 600×). Regressive changes to pancreatic islet cells.

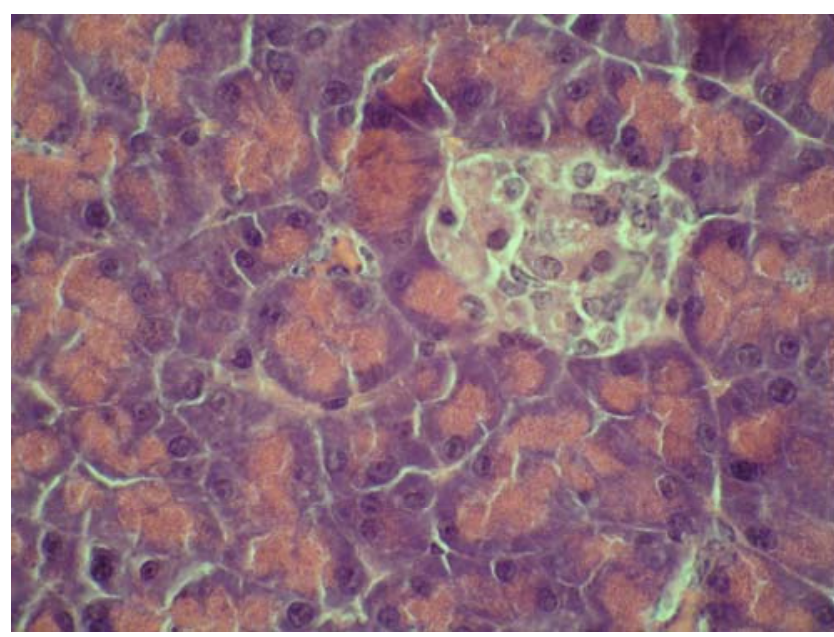


Figure 5. Microphotograph of pancreas - the effect of diplacone (1) on the pancreatic histopathology of diabetic mice (HE 600×). Pancreatic islet with an irregular shape; with vacuolised cytoplasm, a pyknotic nucleus and tiny necrosis without a significant inflammatory reaction.

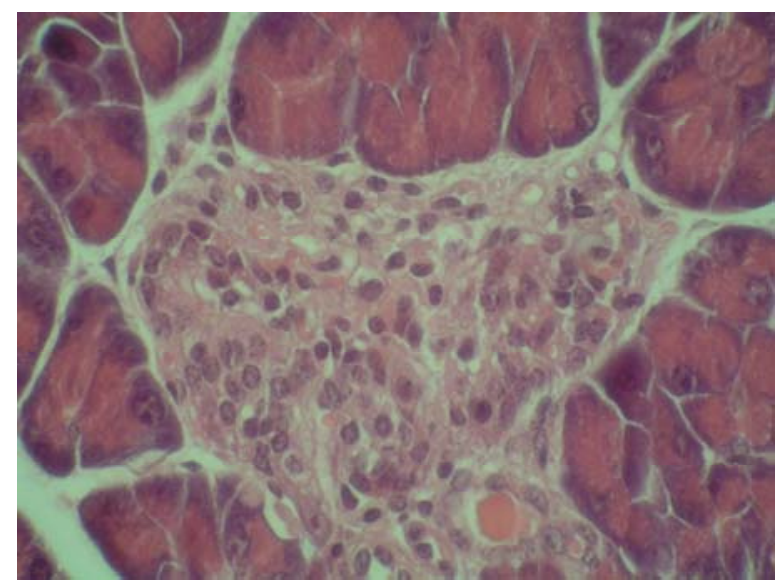

\section{Experimental}

\subsection{Tested compounds}

C-6 geranylated flavonoids 1-8 were isolated from $P$. tomentosa fruit $[9,10]$. Schizolaenone C (9) and 6-isopentenyl-3'-O-methyltaxifolin (10) were isolated from $P$. tomentosa fruit as well (Table 1) $[9,30]$. As a standard for comparing the activities of the compounds that rutin (Fluka ${ }^{\circledR}$ ), morine $\left(\right.$ Sigma-Aldrich $\left.^{\circledR}\right)$ and Trolox ${ }^{\circledR}\left(\right.$ Sigma-Aldrich $\left.^{\circledR}\right)$ were used. The purity of all the compounds tested was checked via HPLC analysis and exceeded 95\%.

\subsection{ABTS and DPPH scavenging activity}

The antiradical activity of the compounds was determined spectrophotometrically in the Microplate Reader Synergy HT (Bio-Tek Instruments, Inc) in 96 wells plates in kinetic mode. The DPPH and ABTS assay followed modified methods of Brand-Williams et al. [31] and Arnao et al. [32], respectively. DPPH test: reaction mixture contained DPPH $(63.4 \mu \mathrm{M})$ and different concentrations of samples in final volume of $300 \mu \mathrm{L}$. Detection at $517 \mathrm{~nm}$. All components were dissolved in methanol. ABTS test: the reaction mixture contained ABTS $(83.4 \mu \mathrm{M}$, in phosphate buffer $\mathrm{pH} 7.4)$ and different concentrations of samples in final volume of $350 \mu \mathrm{L}$. Detection wavelength was $734 \mathrm{~nm}$. Samples were dissolved in ethanol. All experiments were performed in triplicate. Activity of the tested compounds was expressed as TEAC.

\subsection{FRAP}

A colorimetric assay, according to Benzie and Strain, was used [33]. Activity was measured spectrophometrically at $593 \mathrm{~nm}$. The reaction mixture contained TPTZ $(0.83 \mathrm{mM}), \mathrm{FeCl}_{3}(1.67 \mathrm{mM})$ and an acetate buffer $(250 \mathrm{mM}, \mathrm{pH} 3.6)$. The total volume of the reaction mixture was $3 \mathrm{~mL}$. Samples 
were measured in triplicates for 6 min in kinetic mode. The results are presented as the equivalent of the Trolox ${ }^{\circledR}$.

\subsection{Inhibition of peroxynitrite induced tyrosine nitration}

A peroxynitrite solution was prepared and an assay carried out according to the method mentioned previously [34]. The percentage of the inhibition of tyrosine nitration was compared to that of the calibrated $\operatorname{Trolox}^{\circledR}$ standard. The results are expressed in terms of Trolox $^{\circledR}$ equivalent antioxidant capacity.

\subsection{Superoxide scavenging activity}

Modified enzymatic and non-enzymatic assays described by Valentaõ et al. for the generation of superoxide radical were used [22]. Both methods used spectrophotometric detection at $562 \mathrm{~nm}$, using 96 wells plates and the microplate reader Synergy HT. The assay was performed at room temperature. Samples and standard were measured in equimolar concentrations of $50 \mu \mathrm{M}$ and subsequently compared. All experiments were performed in triplicate. Activity of the samples was compared with rutin.

\subsubsection{Enzymatic assay}

The reaction mixture consisted of xanthine $(380 \mu \mathrm{M}$, in $1 \mu \mathrm{M} \mathrm{NaOH})$, xanthinoxidase $(0.025 \mathrm{U} / \mathrm{mL}$, in $0.1 \mathrm{mM}$ EDTA), NBT $(42.3 \mu \mathrm{M}$, in a $50 \mathrm{mM}$ phosphate buffer with $0.1 \mathrm{mM}$ EDTA, $\mathrm{pH} 7.8)$ and the tested compounds (in DMSO). The final volume of the reaction mixture was $350 \mu \mathrm{L}$. The reaction was initiated by the addition of $\mathrm{XO}$ and proceeded for $2 \mathrm{~min}$. at room temperature.

\subsubsection{Non-enzymatic assay}

Superoxide was generated in system NADH/PMS. The reaction mixture contained NADH $(166 \mu \mathrm{M})$, NBT $(43 \mu \mathrm{M})$, PMS $(2.7 \mu \mathrm{M})$, the tested compounds in final volume $300 \mu \mathrm{L}$. All components were dissolved in $19 \mathrm{mM}$ phosphate buffer ( $\mathrm{pH}$ 7.4). Compounds were dissolved in DMSO. The reaction was initiated by the addition of PMS and proceeded for 2 min at room temperature.

\subsection{Inhibition Fenton reaction assay}

This assay was proposed in order to evaluate the capacity of compounds to scavenge $\mathrm{OH}^{\bullet}$ and, consequently, to protect DNA from oxidative degradation. To supply $\mathrm{OH}^{*}$, a mixture of $\mathrm{Fe}(\mathrm{III}), \mathrm{H}_{2} \mathrm{O}_{2}$ and ascorbic acid was used. Ascorbic acid reduces $\mathrm{Fe}(\mathrm{III})$ to $\mathrm{Fe}(\mathrm{II})$, providing a constant flux of $\mathrm{OH}^{*}$. The following equations illustrate the Fenton reaction:

$$
\begin{gathered}
\mathrm{Fe}^{3+}+\text { ascorbate } \rightarrow \mathrm{Fe}^{2+}+\text { oxidized ascorbate } \\
\mathrm{Fe}^{2+}+\mathrm{H}_{2} \mathrm{O}_{2} \rightarrow \mathrm{Fe}^{3+}+\mathrm{OH}^{\bullet}+\mathrm{OH}^{-} \\
\mathrm{OH}^{\bullet}+\text { DNA } \rightarrow \text { DNA damage product }+\mathrm{OH}^{-}
\end{gathered}
$$


The degradation of plasmid DNA was used as a marker of oxidative damage. Supercoiled plasmid pUC19 was isolated from Escherichia coli TOP10F' using a QIAprep Spin Miniprep Kit (QIAGEN, Hilden, Germany). This plasmid (300 ng per reaction) was mixed with compounds dissolved in DMSO and tested in two final ratios of 50:1 and 10:1 (the number of molecules of the tested compound: $1 \mathrm{bp}$ [base pair]), both in the presence or absence of every single intervening agent in the Fenton reaction. Ratio 1:1 was also used, but it was removed from the evaluation because of ambiguous results, which were observed with some compounds. DMSO and rutin were used as negative and positive controls, respectively. A solution of the tested compound was added into a microtube and a TE buffer was used to fill up to the final volume level of $20 \mu \mathrm{L}$. This was followed by the addition of $12 \mu \mathrm{L}$ of the established Fenton reaction mixture, with the final concentrations of $0.66 \mathrm{mM} \mathrm{H}_{2} \mathrm{O}_{2}, 0.66 \mathrm{mM} \mathrm{FeSO}_{4}$ and $0.83 \mathrm{mM}$ ascorbic acid. Reaction mixtures were incubated at $37{ }^{\circ} \mathrm{C}$ for 1 hour and then analyzed using electrophoresis $[0.8 \%$ agarose gel, voltage $5 \mathrm{~V} / \mathrm{cm}$, visualized by ethidium bromide staining $(0.15 \mathrm{mg} / \mathrm{mL})]$ (Figure 6). Visualization was performed on a UV transilluminator $(\lambda 312 \mathrm{~nm})$. The electrophoreogram was captured and analyzed by AlphaEaseFC software, version 4.0.0.34 (Alpha Innotech, USA). The relative percentages of circular (CCC) form, one strand nicked (OC) form and linear (L) form of plasmid DNA were evaluated by measurement of the intensity of individual bands. Afterwards, the quantity of different plasmid forms was expressed as an AUC of peaks obtained on the basis of bands intensity. Any compound tested did not digest plasmid, when it was incubated alone with plasmid (data not shown).

Figure 6. Typical electrophoreogram showing the ability of the individual compound to protect DNA in vitro. Lane 1-3: pUC19 + Fenton reaction + 1 (50:1, 10:1, 1:1); Lane 4: pUC19 + 1 50:1; Lane 5-7: pUC19 + Fenton reaction + rutin $(50: 1,10: 1,1: 1)$; Lane 8: pUC19 + rutin 50:1; Lane 9: pUC19 + Fenton reaction + DMSO (vehicle); Lane 10: pUC19 L-form; Lane 11: pUC19 native form; Lane 12: ladder.

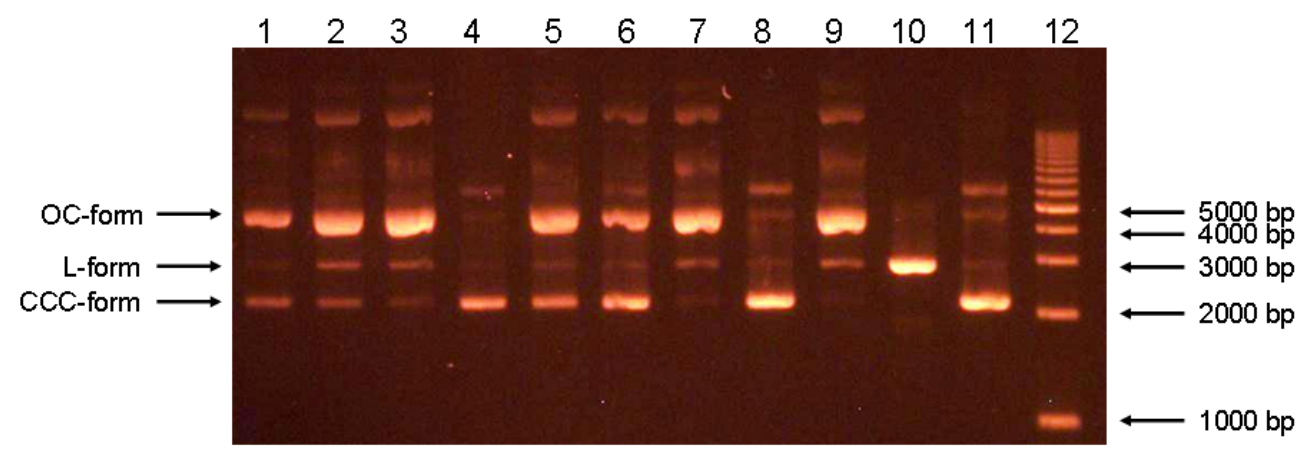

\subsection{Cytoprotective effect against alloxan-induced diabetes}

The in vivo test of antioxidant activity studied the protective effect of flavonoid compounds from $P$. tomentosa (1-8) in mouse model of alloxan-induced diabetes mellitus. This experiment was divided into two steps. First, as a pre-screening, the cytoprotective activity of compounds 1-8 was evaluated (data not shown). According to the pre-screening results we decided to target on the activity of diplacone (1) and mimulone (2), both at two concentrations $(0.5 \mathrm{mmol} / \mathrm{kg}$ and $1 \mathrm{mmol} / \mathrm{kg}$ body weight). 
Female ICR (imprinting control region) albino mice (30-40 g; Anlab, Czech Republic) were used in the experiment. The animals were placed individually in glass metabolic cages at a temperature of 20-24 ${ }^{\circ} \mathrm{C}$, fed a standard diet and given water ad libitum. The mice were divided into seven groups, each with 10 members: 4 pretreated with the tested compounds in two concentrations, one positive control (only alloxan solution administered), one negative control (isotonic saline solution administered) and one group pretreated with morine known to be a good antioxidant [35].

The tested compounds and alloxan monohydrate were dissolved in a $10 \%(\mathrm{v} / \mathrm{v})$ DMSO diluted by an aqua pro injectione. The solution of the tested compounds was administered to the mice intraperitoneally (at doses of $0.5 \mathrm{mmol} / \mathrm{kg}$ and $1 \mathrm{mmol} / \mathrm{kg}$ body weight). The alloxan solution $(12 \mathrm{mg} / \mathrm{mL})$ was injected into the tail vein $(0.1 \mathrm{~mL} / 10 \mathrm{~g}$ body weight $) 30 \mathrm{~min}$ after the application of the tested compounds solution. The experiment was carried out for 5 days, the first day was expressed as day 0 . The initial glucose levels were measured in the intact mice. During the next 4 days of the experiment, the glucose levels were measured in the morning after at least $3 \mathrm{~h}$ of fasting (Day 2-5). One-drop glucose oxidase test and blood glucose reflective photometer Glucotrend ${ }^{\circledR} 2$ with Glucotrend $^{\circledR}$ Glucose (max. concentration $33.3 \mathrm{mM}$; Roche, Germany) test strips were used to determine glucose concentrations (mM) in the venous blood. On the 4th day of the experiment, the animals were destroyed and exsanguinated with pancreas samples taken for histopathological analysis. Samples were fixed in a neutral $10 \%$ formol and routinely stained by hematoxyline-eosine. The preparations were examined in an optical microscope, and the observed changes in glucose levels were statistically evaluated using the ANOVA method.

All aspects of animal care complied with the ethical guidelines and technical requirements, and were proven to be consistent with the Animal Scientific Procedures Act 86/609/EC. The state of health of all animals was regularly examined several times a day during both the period of the animal's acclimation and the whole course of the experiment, by the working team whose members are holders of the Certificate on Professional Competence issued by the Central Commission for the Animal Protection pursuant to $\S 17$ of the Act on Protection of Animals against Cruelty (No. 246/1992 Coll.) of the Czech National Council.

\section{Conclusions}

The antioxidant activities of different flavonoids with a geranyl (compounds 1-9) or a prenyl substitution (compound 10) at position 6 and different substitutions at B and C ring were analyzed. Activity was determined using in vitro methods - ABTS, DPPH, FRAP, the inhibition of peroxynitriteinduced tyrosine nitration, superoxide scavenging and the inhibition of Fenton reaction assay. A single in vivo test was used for the monitoring of cytoprotective effects of compounds $\mathbf{1}$ and $\mathbf{2}$ against alloxan-induced diabetes.

Some of the tested compounds showed notable anti-oxidant activity. The compounds were compared with standards $\operatorname{Trolox}^{\circledR}$, rutin, and with morine in the case of the evaluation of cytoprotective effect in vivo. Generally, the highest activity was shown to be compounds $\mathbf{1}$ and $\mathbf{6}$ with an ortho dihydroxy substitution at the B ring of the flavonoid skeleton. The structure vs. antioxidant activity of the evaluated flavonoids was discussed. Studies on the structure-activity relationship have shown and confirmed that the presence of hydroxyl groups and methoxy groups at the A and B rings 
appear to be important in the antioxidant and free radical scavenging activities of flavonoid compounds. The conclusions of this study have demonstrated that the fruits of $P$. tomentosa provide an efficacious source of natural antioxidant-active substances.

\section{Acknowledgements}

This project was supported by the Internal Grant Agency of the University of Veterinary and Pharmaceutical Sciences Brno, grant number IGA VFU 71/2007 FaF (A.Z.)

\section{References and Notes}

1. Cadenas, E. Biochemistry of oxygen toxicity. Ann. Rev. Biochem. 1989, 58, 79-110.

2. Sies, H. Oxidative stress: Oxidants and antioxidants. Exp. Physiol. 1997, 82, 291-295.

3. Mates, J.M.; Perez-Gomez, C.; De Castro, I.N. Antioxidant enzymes and human diseases. Clin. Biochem. 1999, 32, 595-603.

4. McCall, M.R.; Frei, B. Can antioxidant vitamins materially reduce oxidative damage in humans? Free Radical Biol. Med. 1999, 26, 1034-1053.

5. Pietta, P.G. Flavonoids as antioxidants. J. Nat. Prod. 2000, 63, 1035-1042.

6. Šmejkal, K.; Holubová, P.; Zima, A; Muselík, J.; Dvorská, M. Antiradical activity of Paulownia tomentosa (Scrophulariaceae) extracts. Molecules 2007, 12, 1210-1219.

7. Havsteen, B.H. The biochemistry and medical significance of the flavonoids. Pharmacol. Ther. 2002, 96, 67-202.

8. Rice-Evans, C.A.; Miller, N.J.; Paganga, G. Structure-antioxidant activity relationships of flavonoids and phenolic acids. Free Radical Biol. Med. 1996, 20, 933-956.

9. Šmejkal, K.; Grycová, L.; Marek, R.; Jankovská, D.; Forejtníková, H.; Vančo, J.; Suchý V. Cgeranyl compounds from Paulownia tomentosa fruits. J. Nat. Prod. 2007, 70, 1244-1248.

10. Šmejkal, K.; Chudík, S.; Klouček, P.; Marek, R.; Cvačka, J.; Urbanová, M.; Julínek, O.; Kokoška, L.; Šlapetová, T.; Holubová, P.; Zima, A.; Dvorská, M. Antibacterial C-geranyl flavonoids from Paulownia tomentosa fruits. J. Nat. Prod. 2008, 71, 706-709.

11. Asai, T.; Hara, N.; Kobayashi, S.; Kohshima, S.; Fujimoto, Y. Geranylated flavanones from the secretion on the surface of the immature fruits of Paulownia tomentosa. Phytochemistry 2008, 69, 1234-1241.

12. Van den Berg, R.; Haenen, G.R.M.M.; Van den Berg, H.; Bast, A. Applicability of an improved Trolox equivalent antioxidant capacity (TEAC) assay for evaluation of antioxidant capacity measurements of mixtures. Food Chem. 1999, 66, 511-517.

13. Cao, G.; Sofic, E.; Prior, R.L. Antioxidant and prooxidant behavior of flavonoids: structureactivity relationships. Free Radical Biol. Med. 1997, 22, 749-760.

14. Sekher Pannala, A.; Chan, T.S.; O’Brien, P.J.; Rice-Evans, C.A. Flavonoid B-ring chemistry and antioxidant activity: fast reaction kinetics. Biochem. Biophys. Res. Commun. 2001, 282, 1161-1168.

15. Dugas, A.J., Jr.; Castaneda-Acosta, J.; Bonin, G.C.; Price, K.L.; Fischer, N.H.; Winston, G.W.; Evaluation of the total peroxyl radical scavenging capacity of flavonoids: structure-activity relationships. J. Nat. Prod. 2000, 63, 327-331. 
16. Heim, K.E.; Tagliaferro, A.R.; Bobilya, D.J. Flavonoid antioxidants: chemistry, metabolism and structure activity relationships. J. Nutr. Biochem. 2002, 13, 572-584.

17. Firuzi, O.; Lacanna, A.; Petrucci, R.; Marrosu, G.; Saso, L. Evaluation of the antioxidant activity of flavonoids by "ferric reducing antioxidant power" assay and cyclic voltammetry. Biochim. Biophys. Acta 2005, 1721, 174-184.

18. Muselík, J.; García-Alonso, M.; Martín-López, M.P.; Žemlička, M.; Rivas-Gonzalo, J.C. Measurement of antioxidant activity of wine catechins, procyanidins, anthocyanins and pyranoanthocyanins. Int. J. Mol. Sci. 2007, 8, 797-809.

19. Cos, P.; Li, Y.; Calomme, M.; Jia, P.H.; Cimanga, K.; Van Poel, B.; Pieters, L; Vlietinck, A.J.; Van den Berghe, D. Structure-Activity Relationship and classification of flavonoids as inhibitors of xanthine oxidase and superoxide scavengers. J. Nat. Prod. 1998, 61, 71-76.

20. Borges, F.; Fernandes, E. Progress towards the discovery of XO inhibitors. Curr. Med. Chem. 2002, 24, 195-217.

21. Yao, H.; Liao, Z.X.; Wu, Q; Lei, G.Q.; Liu, Z.J.; Chen, D.F; Chen, J.K.; Zhou, T.S. Antioxidative flavanone glycosides from the branches and leaves of Viscum coloratum. Chem. Pharm. Bull. 2006, 54, 133-135.

22. Valentaõ, P.; Fernandes, E.; Carvalho, F.; Andrade, P.B.; Seabra, R.M.; Bastos, M.L. Antioxidant activity of Centaurium erythraea infusion evidenced by its superoxide radical scavenging and xanthine oxidase inhibitory activity. J. Agric. Food Chem. 2001, 49, 3476-3479.

23. Gutteridge, J.M.C. Iron promoters of the Fenton reaction and lipid peroxidation can be released from haemoglobin by peroxides. FEBS Lett. 1986, 201, 291-295.

24. Kang, J.H. Oxidative damage of DNA by the reaction of amino acid with methylglyoxal in the presence of Fe(III). Int. J. Biol. Macromol. 2003, 33, 43-48.

25. Prakash, D.; Suri, S.; Upadhyay, G.; Singh, B.N. Total phenol, antioxidant and free radical scavenging activities of some medicinal plants. Int. J. Food Sci. Nutr. 2007, 58, 18-28.

26. Szkudelski, T. The Mechanism of Alloxan and Streptozocin Action in B Cells of the Rat Pancreas. Physiol. Res. 2001, 50, 536-546.

27. Rahimi, R.; Nikfar, S.; Larijani, B.; Abdollahi, M. A review on the role of antioxidants in the management of diabetes and its complications. Biomed. Pharmacother. 2005, 59, 365-373.

28. Soto, C.; Recoba, R.; Barron, H.; Alvarez, C.; Favari, L. Silymarin increases antioxidant enzymes in alloxan-induced diabetes in rat pancreas. Comp. Biochem. Physiol. - Part C Toxicol. Pharmacol. 2003, 136, 205-212.

29. Rice-Evans, C; Packer, P. Flavonoids in Health and Disease, 2nd ed.; CRC Press: New York, NY, USA, 2003; pp. 329-334.

30. Šmejkal, K.; Svačinová, J.; Šlapetová, T.; Schneiderová, K.; Dall’Acqua, S.; Innocenti, G.; Závalová, V.; Kollár, P.; Chudík, S.; Marek, R.; Julínek, O.; Urbanová, M.; Kartal, M.; Csöllei, M.; Doležal, K. Cytotoxic activities of several geranyl-substituted flavanones. J. Nat. Prod. 2010, 73, 568-572.

31. Brand-Williams, W.; Cuvelier, M.E.; Berset, C. Use of a Free Radical Method to Evaluate Antioxidant Activity. Food Sci. Technol. 1995, 28, 25-30.

32. Arnao, M.B.; Cano, A.; Acosta, M. The hydrophilic and lipophilic contribution to total antioxidant activity. Food Chem. 2001, 73, 239-244. 
33. Benzie, I.F.F.; Strain, J.J. The ferric reducing ability of plasma (FRAP) as a measure of ,antioxidant power“: the FRAP assay. Anal. Biochem. 1996, 239, 70-76.

34. Vančo, J.; Marek, J.; Trávníček, Z.; Račanská, E.; Muselík, H.; Švajnelová, O. Synthesis, structural characterization, antiradical and antidiabetic activities of copper(II) and zinc(II) Schiff base complexes derived from salicylaldehyde and $\beta$-alanine. J. Inorg. Biochem. 2008, 102, 595-605.

35. Subash, S.; Subramanian, P. Morin a flavonoid exerts antioxidant potential in chronic hyperammonemic rats: a biochemical and histopathological study. Mol. Cell Biochem. 2009, 327, 153-161.

Sample Availability: Samples of compounds 1-8 are available from the authors.

(C) 2010 by the authors; licensee MDPI, Basel, Switzerland. This article is an Open Access article distributed under the terms and conditions of the Creative Commons Attribution license (http://creativecommons.org/licenses/by/3.0/). 